\title{
Acquisition and transfer of feature-negative discriminations
}

\author{
JENNIFER LAMARRE and PETER C. HOLLAND \\ University of Pittsburgh, Pittsburgh, Pennsylvania
}

\begin{abstract}
This experiment examined the acquisition and transfer of inhibitory stimulus control in serial feature-negative $(\mathrm{A}+, \mathrm{X} \rightarrow \mathrm{A}-)$ discriminations in a conditioned suppression situation. A variety of visual and auditory stimuli were used as $A$ and $X$ in separate groups of rat subjects. The choice of the stimuli used as $\mathrm{X}$ and $\mathrm{A}$ substantially affected the rate of acquisition of those discriminations. But in no case did X inhibit conditioned responding to another excitor that was separately paired with the unconditioned stimulus. These results replicated, over a wide range of acquisition rates and performance levels, Holland and Lamarre's (Learning and Motivation, 1984) observation that the inhibitory stimulus control established to the feature in serial feature-negative discrimination procedures was highly specific to the excitor with which it had been trained.
\end{abstract}

Holland and Lamarre (1984) showed that the nature of inhibitory stimulus control established to the $\mathrm{X}$ feature stimulus in an A+, XA - feature-negative (Jenkins \& Sainsbury, 1969) or conditioned inhibition (Pavlov, 1927) procedure depended on the temporal arrangement of $\mathrm{X}$ and $\mathrm{A}$ on the compound trials during training. In a conditioned suppression preparation with rat subjects, we found that if $X$ and A were presented simultaneously in training, $X$ reduced responding to another, previously established excitor (B) when $\mathrm{X}$ and $\mathrm{B}$ were later presented in compound. But if $\mathrm{X}$ preceded $\mathrm{A}$ on compound training trials, $\mathrm{X}$ did not reduce subsequent test responding to B. These and other data (Holland, 1984) led us to suggest that inhibitors established using the simultaneous procedure may modulate conditioned behavior by acting on a representation of the unconditioned stimulus (US), but inhibitors established with the serial procedure may act on particular CS (conditioned stimulus)-US associations. More casually, an X feature trained within a simultaneous feature-negative procedure may signal a period of safety or the nonoccurrence of the US. Thus, a simultaneously trained feature should inhibit any conditioned behavior mediated by that US (i.e., conditioned responses to any CS associated with that US). Conversely, the serial feature-negative procedure endows $\mathrm{X}$ with the ability to negate the action of the $A \rightarrow$ US association, that is, to indicate that $A$ will not on that occasion be followed by the US. Because $\mathrm{X}$ acts on a particular $\mathrm{A} \rightarrow \mathrm{US}$ association, it would be expected to inhibit only responding generated by that association, that is, responding to $\mathrm{A}$.

In this experiment, we extended Holland and Lamarre's (1984) findings by examining the effects of variations in the physical properties of $\mathrm{A}$ and $\mathrm{X}$ on the acquisition and

This research was supported in part by a grant from the National Institute of Mental Health. Reprints are not available. The authors' mailing address is: Department of Psychology, University of Pittsburgh, Pittsburgh, PA 15260. transfer of inhibitory stimulus control in serial featurenegative $(\mathrm{A}+, \mathrm{X} \rightarrow \mathrm{A}-)$ discriminations. Rescorla and Furrow (1977) found that the use of similar A and X stimuli in an $\mathrm{A}+, \mathrm{X} \rightarrow \mathrm{A}$ - procedure facilitated the acquisition of second-order conditioning to $X$ (note that the intermixing of $\mathrm{A}+$ " "refresher" trials with $\mathrm{X} \rightarrow \mathrm{A}$ secondorder trials renders the second-order conditioning procedure identical to the serial feature-negative discrimination procedure). Furthermore, Nairne and Rescorla (1981) suggested that the use of similar stimuli changed the character of that second-order conditioning: "S-S" associations between $X$ and $A$ were observed when $X$ and $A$ were similar, but " $S-R$ " associations between $X$ and a putative emotional response to A predominated when $\mathrm{X}$ and $\mathrm{A}$ were dissimilar.

In this experiment we considered whether variations in the similarity between the feature $(\mathrm{X})$ and the common element (A) would affect the acquisition rate and/or character of inhibitory learning in serial feature-negative discrimination procedures. LoLordo and Fairless (1984) have reviewed a number of potential effects of similarity on the acquisition and content of feature-negative discriminations. For example, learning a negative relation between $X$ and the $A \rightarrow$ US relation (Holland, 1984) might be encouraged if the latter unit possessed an element that was similar to X. Similarly, LoLordo and Fairless noted that similarity between the feature and common element is often found to enhance conditioned inhibition to the feature in simultaneous feature-negative procedures. Consequently, similar stimuli might permit the learning of the $\mathrm{X} \rightarrow$ no-US relation under less optimal stimulus conditions, such as with serial compound stimuli. Because learning that relation (rather than the negative relation between $X$ and the $A \rightarrow U S$ unit) endows $X$ with the ability to depress responding to any CS paired with that US, more transfer might be observed when similar stimuli are used as $\mathrm{X}$ and $\mathrm{A}$.

More empirically, the examination of transfer after 
feature-negative discrimination training that involves a variety of stimulus combinations potentially could extend Holland and Lamarre's (1984) findings to discrimination procedures that encourage different rates and levels of serial feature-negative discrimination performance. It could be argued, for example, that acquisition rate, rather than the temporal arrangement of cues, was the critical determinant of whether inhibitory control of a feature would transfer to another excitor in those studies.

This experiment used feature and common-element stimuli that were either similar or different in their presentation mode. Holland and Ross (1981) found that withincompound learning occurred more rapidly in serial compound conditioning when the two stimuli involved were both intermittent or both steady than when one was intermittent and one was steady. In this experiment, either an intermittent or a steady houselight feature was paired with an intermittent or a steady noise or tone common element.

\section{METHOD}

\section{Subjects}

The subjects were 22 female and 10 male experimentally naive, locally bred albino rats that were 140-170 days old at the beginning of the experiment. The rats lived in individual cages in a colony room illuminated from 6:00 a.m. to 8:00 p.m. daily; experimental sessions were conducted between 8:00 a.m. and 3:00 p.m. The rats had free access to water but were maintained at $80 \%$ of their normal weights by restricting their access to food.

\section{Apparatus \\ There were eight identical experimental chambers, each $22.9 \times 20.3 \times 20.3 \mathrm{~cm}$. The floor of each chamber was made of .48 - $\mathrm{cm}$ stainless steel rods spaced $1.9 \mathrm{~cm}$ apart. The two end walls were aluminum; the side walls and top were clear acrylic. Two centimeters to the right of the center of one end wall was a food cup recessed be- hind a $5 \times 5 \mathrm{~cm}$ opening. Two centimeters to the left of the center of that wall was a $2.5 \times 2.5 \mathrm{~cm}$ response lever. A jeweled signal lamp was located above and between the food-cup opening and the response lever; this lamp was not illuminated at any time. On the opposite end wall, an identical food cup projected $3.8 \mathrm{~cm}$ into the chamber; this food cup was not used in these experiments. Each chamber was enclosed in a light- and sound-resistant closet. A speaker and a 6-W houselight were mounted on the inside wall of each closet enclosure, about $10 \mathrm{~cm}$ above and behind the experimental chamber.}

\section{Procedure}

All rats were magazine trained in two 1-h sessions in which 45-mg food pellets were given on a variable-time (VT) 1-min schedule. Leverpress training sessions, in which each leverpress was followed by the delivery of a food pellet, were given as necessary; each rat was removed after it had made approximately 50 leverpresses. Hand shaping was used for some rats. Next, all rats received one 90 -min session in which leverpresses were reinforced on a variable-interval (VT) 1-min schedule and then five 90 -min sessions on a VI 2-min schedule.

All phases of this experiment were conducted on the leverpress baseline; session duration was always $90 \mathrm{~min}$. First, all rats received two pretest sessions, each of which included six 1-min nonreinforced presentations of the houselight to be used as the negative feature. For half of the rats, that houselight was intermittent $(2 \mathrm{~Hz} ; \mathrm{Li})$, and for the other half it was steady (Ls). Next, all subjects received a single conditioning session in which each of two 1-min presentations of the stimulus to be used as the common-element excitor was followed by a 0.5 -sec 0.5 $\mathrm{mA}$ shock. For different groups of subjects, that stimulus was a steady $82-\mathrm{dB}$ white noise $(\mathrm{Ns})$, an intermittent $(2-\mathrm{Hz})$ white noise $(\mathrm{Ni})$, a steady $82-\mathrm{dB} 1500-\mathrm{Hz}$ tone $(\mathrm{Ts})$, or an intermittent $(2-\mathrm{Hz})$ tone $(\mathrm{Ti})$.

Then the rats received 24 feature-negative discrimination training sessions. All possible combinations of steady or intermittent houselight fea- ture with steady or intermittent noise or tone common element were given, one in each of eight groups of four subjects. The group names designated the stimuli used as the feature and the common element; for example, Group LsTs received nonreinforced trials on which the steady houselight was followed by a steady tone.

Next, the subjects received a single conditioning session that included two reinforced 1-min presentations of another excitor. For all subjects, that excitor differed from the original excitor in both stimulus quality (noise or tone) and presentation mode (steady or intermittent). For example, in this phase, the subjects in Group LsTs received training with the intermittent noise. Finally, all subjects received two test sessions in which two nonreinforced presentations each of the original excitor alone, the new excitor, the original serial compound, and a new serial compound comprising the original houselight feature and the new excitor were given in counterbalanced order.

The measure of conditioning was a standard suppression ratio (Annau \& Kamin, 1961) computed by dividing the response rate during CS presentations by the sum of response rates during CS presentations and for $2 \mathrm{~min}$ prior to CS presentations. With this measure, a score of 0 indicates complete suppression (conditioning), a score of .50 indicates no effect of stimulus presentation, and a score of more than .50 indicates a facilitatory effect of CS presentation. Discrimination performance was measured by constructing a difference score, the suppression ratio to $\mathrm{A}$ on compound trials minus the suppression ratio on A-alone trials.

The level of statistical significance adopted throughout these experiments was $\mathrm{p}<.05$.

\section{RESULTS}

The upper panels of Figure 1 show suppression of responding to the houselight feature stimuli when they were followed by either the tone (left) or the noise (right). Substantial acquisition of suppression to the houselight feature stimuli, presumably the consequence of secondorder conditioning, followed by loss of suppression to the original (pretest) levels, was observed in all groups. A $2 \times 2 \times 2$ distribution-free analysis of variance (ANOVA; Wilson, 1956) of total responding to the houselight stimuli in the discrimination phase, with presentation mode of the houselight, presentation mode of the auditory common element, and identity of the common element (tone or noise) as factors, showed no reliable overall effect of groups $\left[\chi^{2}(7)=2\right]$.

The lower panels of Figure 1 show discrimination difference scores of the groups that received either the tone (left) or the noise (right) as the reinforced element. The pattern of data differed considerably depending on whether the common element in training was the tone or the noise. The subjects that received a tone common element showed a pronounced similarity effect: Discrimination performance was best in the groups in which both feature and common element were intermittent or both were steady. But the subjects that received the noise common element showed only an effect of noise presentation mode: Discrimination performance was superior in the groups that received a steady noise. ANOVA showed only a reliable effect of groups overall $\left[\chi^{2}(7)=22\right]$ and a reliable three-way interaction $\left[\chi^{2}(1)=11.75\right]$. Separate 2 $\times 2$ ANOVAs, with presentation mode of the feature and of the common element as factors, were conducted for the groups for which the common element was the tone and those for which it was the noise. With the tone common element, ANOVA showed only a reliable interac- 

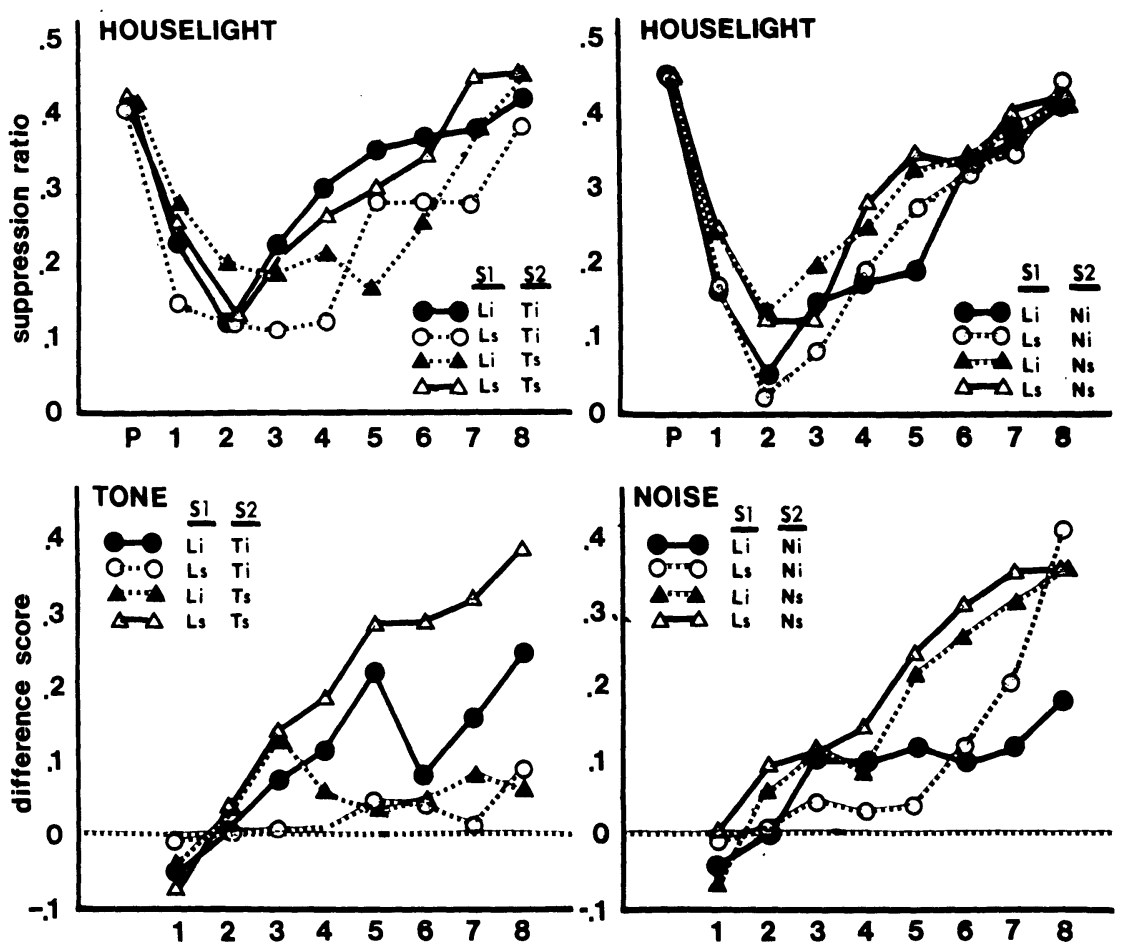

Figure 1. Performance during the discrimination phase. The top panels show suppression to the visual feature S1 stimuli, and the bottom panels show discrimination difference scores. The left panels show the behavior of groups that received the tone as the common element S2, and the right panels show responding in the groups that received the noise as the common element $\mathbf{S 2}$. $\mathbf{L i}=$ intermittent light, $\mathbf{L s}=$ steady light, $\mathbf{T i}=$ intermittent tone, $\mathrm{Ts}=$ steady tone, $\mathbf{N i}=$ intermittent noise, and Ns = steady noise.

tion (which indicated the similarity effect) $\left[\chi^{2}(1)=5\right]$ and only a main effect of presentation mode of the common element for the noise $\left[\chi^{2}(1)=5\right]$.

Figure 2 shows the results of the transfer tests in each of the eight groups. Over all eight groups, suppression was greater to the original training excitor alone than to that stimulus when it was presented after the houselight feature (sign test, $z=4.35$ ), but there was no difference between responding to the new, transfer excitor when it was presented alone and when it was presented within a serial compound $(\mathrm{z}=0.57)$. That pattern was consistent across the groups: The number of subjects that showed transfer of the houselight's inhibitory control to a new excitor did not differ among the groups $\left[\chi^{2}(7)=8\right]$. Thus, variations in the choice of stimuli as the feature and the common element did not affect transfer.

Pre-CS leverpress rates during the test sessions did not differ reliably among the groups $\left[\chi^{2}(7)=4\right]$, although subjects in Group LiTi showed less pre-CS responding (7.3 responses/min) than the subjects in Group LsTs (19.1 responses/min; $U=0$ ). The mean pre-CS rates of the remaining groups ranged from 11.3 to 12.6 responses/min.

\section{DISCUSSION}

The choice of the stimuli used as the feature and common-element stimuli, and their particular combinations, affected the rate acquisition of feature-negative discrimination learning with serial nonreinforced compounds. But in no case did the inhibitory control of the feature stimulus transfer to an excitor other than the one used in discrimination training. Thus, the results of the transfer tests confirm and extend our previous findings (Holland \& Lamarre, 1984).

Elsewhere (Holland \& Lamarre, 1984), we reviewed a number of potential accounts for our failure to observe transfer of inhibitory stimulus control after serial feature-negative discrimination training. The present experiment provided additional data relevant to some of those hypotheses. One possibility is that features that acquire inhibitory control rapidly show transfer, but those that acquire it slowly do not. But, in this experiment, the amount of transfer observed was not related to the speed of discrimination learning. Similarly, in an unpublished experiment, we found that variations in the temporal characteristics of the feature stimuli (differences in the feature/common-element interval and trace vs. delay procedures) affected the rate of acquisition of serial feature-negative discriminations, but did not affect the amount of transfer that was observed (none was observed in any condition).

A second hypothesis is that the lack of transfer observed with serial procedures is the consequence of stronger association between the feature and common element in serial than in simultaneous compounds (e.g., Rescorla, 1973). It is possible that the serial feature may control secondorder conditioned excitation in the period immediately after its presentation. That second-order excitation may sum with the excitation of the new, transfer test excitor to obscure the feature's inhibitory control in transfer tests, but not sum with the excitation of the original excitor, on which the feature's second-order excitation was presumably based (Rescorla, 1982). Or, as Konorski (1967) suggested, the rats might learn to anticipate a particular excitor after the feature. Presentation of another excitor after the feature would then result in a "surprise" or orienting reaction, which might be exhibited as suppression of leverpressing.

To examine these possibilities, at the conclusion of this experiment we gave eight nonreinforced houselight-alone trials in each of four sessions to half of the subjects in each of the groups and four sessions of 


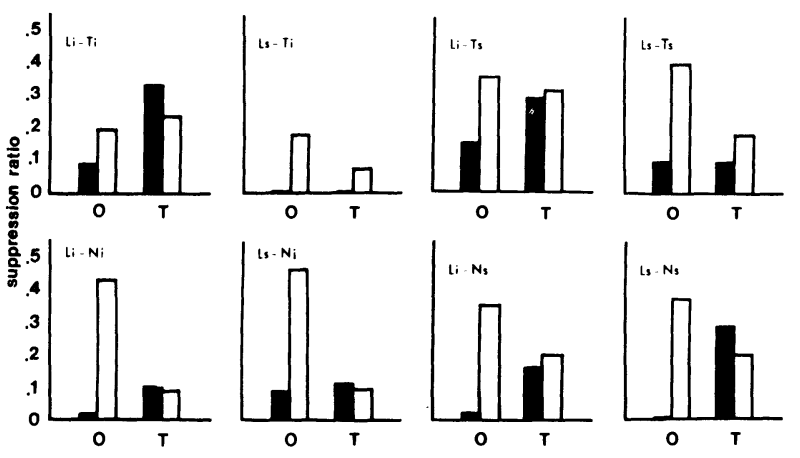

Figure 2. Performance during Tests 1 and 2, combined. Each panel shows the performance of one group, identified by the stimuli used as the feature and common-element stimuli during training. $\mathbf{L i}=$ intermittent light, $\mathbf{L s}=$ steady light, $\mathrm{Ti}=$ intermittent tone, $\mathrm{Ts}=$ steady tone, $\mathrm{Ni}=$ intermittent noise, and $\mathrm{Ns}=$ steady noise. The solid bars signify responding to an excitor alone, and the open bars signify responding to the excitor within a serial compound. The bars labeled " $O$ " show performance on the original discrimination, and the bars labeled "T" show performance to the new excitor and its compound with the houselight feature.

VI training only to the other half. All subjects then received a single test session comprising four presentations each of the serial compound stimulus and the excitor alone that were used in the original training. If the second-order excitation or expectancy controlled by feature interfered with the observation of its inhibitory control, then the extinction of that second-order excitation or expectancy should enhance the apparent inhibitory control of the feature. In fact, presentations of the feature alone reduced its inhibitory control. The subjects that received houselight extinction trials showed a reliable mean decrease of .08 in their discrimination difference scores from the previous test to the postextinction test (Wilcoxon $T=18$ ), whereas the subjects that received only additional VI sessions showed a nonreliable increase in their difference scores (mean $=.07 ; \mathrm{T}=32$ ). The between-treatment difference in the change in difference scores was also reliable $(U=53)$. A subsequent identical test with the transfer excitor revealed no evidence of inhibitory control for either subjects that received houselight presentations or those that did not. Thus, it is unlikely that lingering excitatory control or surprise was responsible for the lack of transfer observed here.

It is worth noting that nonreinforced presentations of a feature trained with simultaneous feature-negative procedures has been found to either increase or have no effect on that feature's inhibitory control (e.g., Pearce, Nicholas, \& Dickinson, 1982; Rescorla, 1982; Witcher \& Ayres, 1984; Zimmer-Hart \& Rescorla, 1974), further suggesting that the nature of inhibitory control established with serial feature-negative discrimination procedures differs from that established with comparable simultaneous procedures. We prefer the notion that serial procedures encourage control by the contingency between the feature and nonreinforcement of the common element (that is, inhibition of the action of the $\mathrm{A} \rightarrow \mathrm{US}$ association), whereas simultaneous procedures encourage control by the contingency between the feature and the nonoccurrence of the US (that is, inhibition of the action of the US).

\section{REFERENCES}

ANnAU, Z., \& Kamin, L. J. (1961). The conditioned emotional response as a function of intensity of the US. Journal of Comparative and Physiological Psychology, 54, 428-432.

Holland, P. C. (1984). The nature of inhibition in serial and simultaneous feature negative discriminations. In R. R. Miller \& N. E. Spear (Eds.), Information processing in animals: Conditioned inhibition (pp. 267-297). Hillsdale, NJ: Erlbaum.

Holland, P. C., \& LamarRe, J. (1984). Transfer of inhibition after serial and simultaneous feature negative discrimination training. Learning and Motivation, 15, 219-243.

Holland, P. C., \& Ross, R. T. (1981). Within-compound associations in serial compound conditioning. Journal of Experimental Psychology: Animal Behavior Processes, 7, 228-241.

Jenkins, H. M., \& SaINSBURY, R. S. (1969). The development of stimulus control through differential reinforcement. In N. J. Mackintosh \& W. K. Honig (Eds.), Fundamental issues in associative learning (pp. 123-161). Halifax: Dalhousie University Press.

KoNORSKI, J. (1967). Integrative activity of the brain. Chicago: University of Chicago Press.

LoLordo, V. M., \& Fairless, J. L. (1984). Pavlovian conditioned inhibition: The literature since 1969. In R. R. Miller \& N. E. Spear (Eds.), Information processing in animals: Conditioned inhibition. Hillsdale, NJ: Erlbaum.

NAIRNe, J. S., \& Rescorla, R. A. (1981). Second-order conditioning with diffuse auditory reinforcers in the pigeon. Learning and Motivation, 12, 65-91.

Pavlov, I. P. (1927). Conditioned reflexes. London: Oxford University Press.

Pearce, J. M., Nicholas, D. J., \& Dickinson, A. (1982). Loss of associability by a conditioned inhibitor. Quarterly Journal of Experimental Psychology, 33B, 149-162.

RESCORLA, R. A. (1973). Second-order conditioning: Implications for theories of learning. In F. J. McGuigan \& D. B. Lumsden (Eds.), Contemporary approaches to conditioning and learning. Washington, DC: Winston.

RESCORLA, R. A. (1982). Some consequences of associations between the excitor and the inhibitor in a conditioned inhibition paradigm. Journal of Experimental Psychology: Animal Behavior Processes, 8, 288-298.

Rescorla, R. A., \& Furrow, D. R. (1977). Stimulus similarity as a determinant of Pavlovian conditioning. Journal of Experimental Psychology: Animal Behavior Processes, 3, 203-215.

WILSON, K. V. (1956). A distribution-free test of analysis of variance hypotheses. Psychological Bulletin, 53, 96-101.

Witcher, E. S., \& AYres, J. J. B. (1984). A test of two methods for extinguishing Pavlovian conditioned inhibition. Animal Learning \& Behavior, 12, 149-156.

Zimmer-Hart, C. L., \& Rescorla. R. A. (1974). Extinction of Pavlovian conditioned inhibition. Journal of Comparative and Physiological Psychology, 86, 837-845. 